\title{
Oficios, costumbres y sociedad en el Madrid bajomedieval
}

\author{
MANUEl MONTERO VALLEJO \\ Real Academia de San Fernando
}

\section{Realidad de Madrid en el Bajo Medievo}

Antes de trazar las líneas de un panorama artístico, una realidad social, unas costumbres, es preciso colocar el soporte. El marco en que se desenvuelven las actividades humanas es previo a ellas. Por esta razón conviene situar en sus justos términos el Madrid bajomedieval. Y a ello nos dedicaremos en primer lugar.

Fijaremos un tiempo concreto como útil referencia: la villa entre mediados del siglo XV y comienzos del XVI. Además, tal fase es muy aprovechable porque supone un momento de crecimiento de la población en todos los órdenes: en lo demográfico, en expansión urbana, en lo económico, en cuanto a importancia.

Madrid había cercado sus hasta entonces dispersos arrabales hacia 1438: la superficie encerrada superaba probablemente las $75 \mathrm{Ha}$. Sin embargo, las densidades humana y de edificación eran bien distintas entre el principio y el final del período que marcamos. A mediados del siglo $\mathrm{xv}$, la villa comenzaba a estirar sus arrabales - algunos, aún muy rurales-, a cubrir de edificios las proximidades de sus cavas y a recuperarse de un estancamiento demográfico. En los inicios de la centuria siguiente sólo parte de la colación de la Almudena - destrozada por los disturbios y contiendas civiles-, la zona septentrional del arrabal de San Martín, el de San Millán - por su carácter semicampesino-, el marginal de Santa Cruz —de reciente formación- y algunos sectores de los fosos permanecen sin edificar. Con todo, los ritmos de crecimiento fueron diferentes; estamos convencidos de que hasta 1480 la progresión se centró en los arrabales. En 1477 aún se conceden beneficios a quienes quisieren instalarse dentro de la muralla:

[...] por quanto la dicha Villa de los muros adentro está mucho despoblada e destruyda a causa de las guerras pasadas, o del çerco que se puso sobre los alcáçares de la dicha Villa, e de las quemas e derrocamientos que se hizieron en la colaçión de Sant Miguel e de Xagra [...] (Montero 1987: 222). 
En cambio, cuando un vecino solicita licencia para construir en las proximidades del Alcázar en 1494, se expresa — tras la resolución de darle otro solar- que no hay lugar dentro de la villa. Aunque exista cierta exageración, queda claro que el panorama había cambiado (Montero 1987: 222). La fiebre edificadora indudablemente ha ido unida al fuerte incremento poblacional, y las muchas cartas de vecindad otorgadas lo demuestran; Madrid probablemente duplicó con creces sus efectivos humanos en el período indicado. Si por muy despoblada que estuviera es difícil para tamaña extensión calcular menos de 4-5.000 almas para 1450, después de media centuria debía rebasar las 10.000. Aún así, con desequilibrio evidente entre áreas rurales casi inocupadas y zonas céntricas -y aún arrabaleras- colmadísimas, no salen más de 130-140 habitantes por Ha. Discrepamos, por ello, de las cifras de Alvar, que pondera la importancia de la población, pero admite menos de la última cifra para el tiempo inmediato a la capitalidad; o de las de Martorell, que la reduce a la mitad para 1530 (Alvar 1993; Martorell 1930).

Este volumen de habitantes sitúa a Madrid en la zona media-alta de las ciudades castellanas, aunque ilustra menos acerca de la importancia; según nuestros cálculos, igualaría en habitantes a entidades de tanto fuste como Burgos; sería inferior a Úbeda, Baeza y Valladolid; superaría a Salamanca, y claramente a Cáceres, Cuenca y Ávila. Por supuesto, no pretendemos establecer comparación con grandes núcleos castellanos y españoles: Segovia, Zaragoza, Barcelona, por no hablar de los "gigantes": Valencia, Granada, Toledo, incluso Sevilla.

¿Qué otros factores podemos considerar? ¿Voto en Cortes? Una de las 18 entidades que lo tenía. ¿Convocatorias de estas asambleas? Varias entre los siglos XIV y XV. ¿Colaciones? 13, pues a las 10 tradicionales se habían incorporado entre los siglos XII-XIII las de San Martín y San Ginés, y antes de 1427 la de Santa Cruz. O sea, un volumen intermedio, tal vez justo reflejo de su relevancia.

Algo flojea la estadística en otro aspecto, pues el Madrid medieval era escaso proporcionalmente en cuanto a conventos y monasterios, aunque rico en ermitas, hospitales y otras instituciones; poseía, en compensación, dos cenobios afamadísimos: Santo Domingo y San Francisco. Mas desde la segunda mitad de la decimoquinta centuria la cifra se incrementa: Santa Clara, Santa Catalina, los dos de La Latina, los jerónimos, hasta alcanzar número notable (Montero 1987: 263 ss).

Otro aspecto a considerar para situar a Madrid en su justo punto es lo tocante a la municipalidad. No nos vale que, desde bastante pronto, tenga asistente o corregidor, que en las dos últimas decenas de siglo se convierte en estable. Sí puede constituir índice del volumen de población 
y posibilidades económicas el número de regidores: 12 eran en 1346, que se llegan a reducir a seis en 1381; según nuestros cálculos, pudieron alcanzar un máximo de 16 en 1490-1500. No puede hablarse de escasa entidad, aunque no se alcanzaron las cifras de otras poblaciones castellanas, y sobre todo andaluzas. La progresiva afirmación del Concejo vino acompañada en los dos últimos decenios de la centuria de la maduración de instituciones bajo su tutela (Montero 1987: 220, 263 y ss).

Un índice interesante nos lo da el conocer el auténtico volumen de las transacciones mercantiles, sobre todo en materia de abastos. Aunque poseemos algunos estudios al respecto (Monturiol 1985; Puñal 2000) ${ }^{1}$, no podemos barajar cantidades con certeza suficiente para todos los productos básicos.

Así pues, creemos que el perfil de la villa tardomedieval es -a falta del último dato- el de un núcleo entre medio y medio-alto, y efectuamos esta precisión porque no todas las magnitudes son parejas y porque carecemos de un estudio comparado del aspecto artesanal. Sin embargo, en lo que toca a Madrid, podemos ofrecer un horizonte bastante completo y, en ciertos casos, incluso aproximaciones con cierto detalle (Montero 1987: $220,226,253,282)^{2}$.

\section{LOS OFICIOS DE MADRID: SU EVOLUCIÓN ENTRE LOS SIGLOS XIII Y XV}

\subsection{Panorama inicial. La tradición musulmana}

Ya antes de mediar el siglo XII surge la especialización profesional de algunos madrileños. Estas noticias, en principio escasas y espaciadas cronológicamente, se van adensando en la centuria siguiente. Ciertos oficios - ligados a actividades primarias de subsistencia - se citan ya en el Fuero, pero son muy pocos: panaderos, carniceros, pescaderos, vinadores, ferreros, carpenteros ... Se ha argumentado la posibilidad de que se incluyeran otros, ya que falta parte del documento.

Ya en nuestra tesis doctoral (Montero 1986: passim) adelantábamos que teníamos datos suficientes para presentar un panorama bastante convincente, pero que nos parecía osado elaborar una estadística por lo amplio

\footnotetext{
${ }^{1}$ La primera autora se centra en los aspectos relativos a la recaudación del Concejo en concepto de tasas o impuestos sobre transacciones de diversos géneros y arrendamientos; el segundo estudia, minuciosamente y por extenso, la producción artesana.

${ }^{2}$ Hablamos sobre diversos indicativos del crecimiento de la villa, pero nos centramos principalmente en el incremento espacial.
} 
del período elegido - hasta mitad del siglo $x v-$, la escasez de noticias para fase tan amplia y la diversidad de fuentes empleadas. Los límites finales se justifican por la existencia para esta época de un volumen mucho más considerable de información ${ }^{3}$.

En una villa medieval, sobre todo de las características y población del Madrid de los siglos XIII y xIv, resulta lógico que los menesteres integrados en el sector primario sean los predominantes. No sólo los alrededores y, en general, el alfoz matritense suministran información, pues no ha de olvidarse que espacios considerables dentro de la muralla tuvieron hasta muy tarde aprovechamiento agrícola. Lo que se explica menos es que tales ocupaciones representen un porcentaje inferior al de las artesanales.

Hemos querido justificarlo con la razón siguiente: los "labradores" ganarían sin discusión si en ellos incluimos todos aquéllos - muchísimosque aparecen como propietarios de tierras. Naturalmente, éstas constituían la base patrimonial de los nobles y prohombres locales. Sin embargo, éstos no trabajaban sus posesiones con sus manos, sino a través de aparceros y sirvientes. Pero estos labriegos, por su humilde condición, poseen escasa relevancia, por lo que apenas son citados. En escalón social y económico más alto se situaban comerciantes, arrendadores y artesanos, que en ocasiones ostentan el don, aunque tal tratamiento no tenga el valor que alcanzará después.

Dentro de las actividades agrarias conviene destacar las especializadas, ligadas a cultivos de regadío. Creemos que la primera referencia específica a huertos es de 1225. Los había, dentro de la villa, en la Xagra, el Pozacho; y fuera, arriba de la Puerta de Valnadú, en lo que durante el siglo $\mathrm{Xv}$ se llamarán las Hontanillas, básicamente la actual plaza de Isabel II.

Si en el siglo XIII a las tradicionales ocupaciones agrícolas parece superponerse un aumento de la actividad ganadera -vinculada a los repobladores, y con un claro objetivo, el aprovisionamiento de cueros-, ya en los decenios últimos de la centuria el predominio corresponde a la agricultura, que parece orientarse progresivamente hacia lo hortícola. Recordemos que el regadío también se extendía al cereal, pues en las

\footnotetext{
${ }^{3}$ Aparte de documentación suelta, nuestra elaboración se basa en el Archivo Histórico Nacional (AHN). Clero. Santo Domingo, carpetas 1353-65, más lo correspondiente a San Martín, más tardío. Se completa con un espigueo en el Archivo de la Secretaría del Ayuntamiento (ARS), principalmente "Minutas de escribanos". Este último material ha sido revisado concienzudamente por Puñal, en su libro que se cita en bibliografía. También tuvimos en cuenta los documentos aportados por Fita (1886).
} 
Hontanillas y Xagra se cultivaba así la cebada o alcaçel. Las excavaciones practicadas en los últimos años parecen confirmar el origen de esta práctica en la tradición musulmana ${ }^{4}$.

Desde muy pronto conservamos testimonio de industrias rurales y artesanales; incluso las últimas debieron estar muy ligadas, en la mayoría de los casos, a la subsistencia o poco más (Pastor 1950; Capella 1962) ${ }^{5}$. Molinos y molineros de cereal y de aceite son citados desde 1203 en Xagra y las afueras de Valnadú.

Aparecen comerciantes en sal y bodegas, aunque en época más tardía. Sastres, traperos y comerciantes de tejidos se mencionan también desde principios del XIII; debían habitar preferentemente en el Vicus Francorum, aledaños de San Martín. Evidentemente, la aparición de mayoristas en ciertos géneros sí apunta a que en determinados aspectos en el Madrid del siglo xiII se daban indicios de una economía de nivel superior, orientada no sólo al mercado local, sino comarcal, aunque éste no rebasara en sus intenciones las aldeas del alfoz. Ello iría parejo a la existencia de las ferias, que no sabemos en qué momento se extinguen.

La muestra quizá más clara de que la economía madrileña rebasaba un marco puramente rural es la temprana presencia de dos actividades artesanas que, en particular la segunda, debió pronto alcanzar alta especialización: la elaboración de materiales de construcción y la industria del cuero. La primera es, a lo largo de los siglos XIII y XIV, bastante más citada, aunque la abundancia no tenía que ir en principio unida a la calidad. Estos oficios tenían indudablemente origen islámico, y nuestra matización se confirma por la circunstancia de que las piezas cerámicas encontradas de los siglos XII y XIII poseen inferior calidad que las anteriores a la presencia cristiana.

Sea como fuere, adoberos, tejeros y alfareros aparecen regularmente citados desde 1242, así como tejares - tal vez algunos fueran explotados por el Concejo- y fornos para teja. Se ubicaban hacia Santo Domingo y algunos hacia San Martín. Con la expansión de la población, en el segundo cuarto del siglo xv se reunieron en la última zona e inmediaciones de la cava de la Puerta del Sol.

De los oficios de otra índole, y junto a los del tejido, son los del cuero los más frecuentes; una disposición al respecto - De coramne-

\footnotetext{
${ }^{4}$ Según lo hallado en excavaciones de la plaza de Oriente y las posteriores de Ramales. Es lamentable no poseer una auténtica memoria de excavación de la primera. Tal vez se mantuvieron las costumbres por el gran porcentaje de mozárabes (ver infra 3.1.).

5 Apenas nada dice, no obstante, Capella sobre esta época.
} 
aparece ya en el Fuero. Hay un peletero en 1203 y los zapateros harán su aparición en el decenio de 1260. Pero la gran explosión de las artes del cuero sucederá en el siglo xv.

En resumen, podemos hablar de una sociedad agrícola, con predominio de este aspecto sobre el ganadero, y dentro de él, importante presencia de los cultivos de regadío. Y una industria muy vinculada al mundo rural, pero con dos ramos que superan este panorama: los del barro y el cuero.

Ya en el siglo XIV se van perfilando un cambio y cierta especialización económica; se percibe en el desarrollo de actividades indicadoras de un aumento y mejora del consumo: taberneros, mesoneros, comerciantes - ¿de telas y mercería? - en las angostas tiendas de la Puerta de Guadalfajara (Montero 1987:185-95).

\subsection{La diversificación profesional del siglo XV}

Hacia 1380 algo ocurre en Madrid. Las actividades de los madrileños se hacen más variadas y especializadas. No es casualidad, porque la villa de entonces -en contraste con la relativa crisis y la inestabilidad política- se va haciendo cortesana. Desde Juan I, los monarcas pasan muchas temporadas en la población y ello se traduce en tres realidades: avecindamiento de servidores reales y algunos nobles; incremento de la demanda y del mercado; la tercera es consecuencia de lo expuesto: más oficios y mayor capacitación, como corresponde a un Madrid más uurbano" (Montero 1993; Montero 1997).

En primer lugar, observamos que los menesteres tradicionales se especializan: son nombrados vaineros, tundidores, jubeteros, guarnicioneros,... En cuanto a los nuevos oficios, algunos se vinculan a la presencia de la Corte: escudero, copero, ballestero del rey... Pero lo llamativo es el grupo de los intelectuales y burócratas; aún resistiéndonos a la estadística, sorprende lo porcentualmente importante de este sector, que prepara la eclosión obrada unos decenios después: abogados, escribanos públicos, un maestro de la gramática...

El cambio del espectro profesional se ha consumado al mediar el siglo $\mathrm{xV}$, y además tenemos las cosas más claras por el espectacular aumento de la documentación, que nos permite efectuar comparaciones sucesivas para los años postreros de la centuria. Ya hace tiempo establecimos cortes con el fin de realizar una constatación lo más rigurosa posible: el primero, en los años centrales de siglo; el segundo, en 1477-82; el tercero, en 1486-92; el cuarto comprende los años de 1493 a 1497; y el últi- 
mo, de 1498 a 1502. Pues bien: para el primer periodo contabilizamos casi medio centenar de oficios distintos; en el segundo contamos 65; en el tercero, 76; en el cuarto, 66; en el final volvemos a la cifra de 76. La disminución relativa en los dos últimos pensamos que se puede interpretar en razón de haber recabado datos de un periodo más corto.

Lo verdaderamente llamativo es la evolución de este panorama. Ya en torno a 1450 se observa un predominio de las actividades artesanales sobre las agrícolas, y un avance de los intelectuales". En un recuento más fiable, el de 1477-82, esto es una evidencia. Los oficios relacionados con la alimentación suman 7 ; los vinculados a la producción y venta de tejidos son 11; los metalúrgicos, 6; en la madera aparecen 3 actividades distintas; otras tantas en la construcción. Las industrias del cuero muestran aquí ya una clara superioridad, compartidas con el tejido, pues alcanzan igual cifra.

Sin embargo, aún es más convincente lo relativo a oficios de lujo o vinculados al puro consumo, porque constituye un elemento revelador de la calidad de vida de la sociedad madrileña del momento: confitero, repostero de plata, relojeros, músicos, pintores... Podríamos incluir aquí menesteres tan exóticos como el de leonero: la presencia de leones en la Corte era habitual desde Juan II. Lo más sorprendente es la relativa abundancia de profesiones liberales: bachilleres; escribanos reales, del Concejo y públicos, amén de uno de libros; físicos; cirujanos; un boticario; un doctor.

Si consideramos el número de personas dedicado a las actividades reseñadas en sentido absoluto, la estadística nos ofrecería un porcentaje de comerciantes, artesanos y liberales de casi el $70 \%$. Es evidente que, aunque haya cambiado la distribución de oficios, la escasísima presencia del sector agrícola nos señala —como en siglos atrás- que las gentes del sector primario han quedado fuera de la constatación documental.

Las cifras de momentos posteriores no hacen sino afirmar la realidad de una villa en constante ascenso económico y social, con nuevas responsabilidades y necesidades. Es frecuente contemplar cómo se conceden cartas de vecindad a personas con oficios inexistentes poco antes.

Es una constante el puesto destacado de quienes se dedican al cuero y a los tejidos, que ocupan siempre en torno al tercio de la población activa; a continuación, y para fines de la centuria, se sitúan los oficios del metal; cercanos, los de la construcción, que se recuperan en los últimos años del siglo; se mantiene al alza el porcentaje de los oficios especializados. Y descienden ligeramente las profesiones intelectuales y liberales, pero no en número, debido al ascenso imparable de la artesanía. Un análisis de este espectro laboral y de su evolución nos lleva a establecer varias fases en el Madrid bajomedieval: 
- Un primer período (fines del siglo XIV y comienzos del XV) en que se produce una discreta especialización artesanal y un sensible crecimiento de la burocracia. Unido a las estancias de la Corte.

- Un segundo período (mediados del xv) en que artesanía y comercio se especializan y en que prosigue el aumento de las profesiones liberales y burócratas. Ligado a la consolidación de un mercado comarcal.

- Un tercer período (último cuarto de siglo) en que se registra aceleración en la actividad comercial y artesanal y en el consumo. Relacionado con el aumento poblacional, el afianzamiento del mercado semanal y la recuperación de las ferias (Montero 1987: 194-5; 296-302; Puñal 2000) ${ }^{6}$.

Capítulo importante sería el referido a la constitución de los gremios. Por lo que sabemos, si sólo fue temprano en puntos localizados de Castilla, aquí no se produjo tal situación, e incluso podemos hablar de fechas más tardías de lo habitual que en poblaciones de similar magnitud, aunque estamos convencidos de que algunas ordenanzas se han perdido ${ }^{7}$.

La excepción -icómo no!- la constituyen el cuero y sus derivados, que ofrecen un muestrario completo, circunstancia que no sólo nosotros hemos destacado. Las primeras Ordenanzas de corambres y zurradores hubieron de reunirse en un largo período, mas no se recopilaron sino en 1481, y después en 1489; más tarde conocieron varias reformas y adiciones (Mendo 1990; Campderá y Moral 1993; Puñal 2000: 147-288) ${ }^{8}$.

\section{LA SOCIEDAD MADRILEÑA A LO LARGO DEL MEDIEVO}

\subsection{La sociedad madrileña entre el siglo XII y el siglo XV}

La ciudad, incorporada a Castilla hacia 1085, contaba con un considerable núcleo de población cristiana anterior -mozárabe- y con un número difícilmente estimable de población musulmana que permaneció. Quizá fue escaso, pero ignoramos la razón exacta en que se fundan quienes creen que todos los moros luego habitantes de Madrid tenían procedencia foránea, ya que en el propio Fuero se distingue entre el moro libre

\footnotetext{
${ }^{6}$ Para esta síntesis, se han utilizado —además de las "Minutas" - los Libros de Acuerdos del concejo, existentes desde 1464.

7 Como ha ocurrido con las ordenanzas de taberneros (1476) y las de traperos, roperos y joyeros (1410) (ARS. 2-243-7; 2-242-14).

${ }^{8}$ Primeras ordenanzas sobre corambres: ARS. 2-309-9. Espléndido el estudio de Punal (2000: 147-288) sobre la industria del cuero.
} 
-mayoritariamente residente de antiguo, por pura lógica- y el moro cautivo (Miguel 1989).

De los islamitas madrileños ya se hablará. Es el turno ahora de la comunidad cristiana, que se vio muy crecida por el refuerzo demográfico de los repobladores, cuya procedencia fundamentalmente castellano-leonesa ya fue señalada por Julio González (1975-6).

Siempre hemos insistido que, con no ser despreciable este contingente, no fue flojo el de los mozárabes. Nos hemos fundado en la presencia de determinadas voces, en las advocaciones parroquiales y, especialmente, en nombres y apellidos, además de alguna característica muy significativa, como es la abundancia de diminutivos.

Hace tiempo llegábamos a la conclusión de que en torno al $40 \%$ de la población matritense del siglo XII-principios del XIII era mozárabe; ciertamente, a lo largo de esta centuria, se produjo un rápido mestizaje entre esta comunidad y las distintas de repobladores, así como la fusión con los francos, que constituían minoría clara, pero influyente, agrupada en el Vicus Sancti Martini.

Pero la tradición mozárabe se perpetuará bastante más allá de la fusión: lo percibimos en que los característicos apodos de raíz mozarábiga se perpetúan hasta el siglo $\mathrm{xv}$, $\mathrm{y}$, curiosamente, en los nombres femeninos. A comienzos de la mencionada centuria - junto a tradicionales advocaciones de raíz latina y germánica-, varias madrileñas conservan nombres mozárabes, presentes desde los primeros tiempos: Illana, Flor, Sol, Galiana, Leocadia (Montero 1987: 176-9).

Mucho ignoramos sobre la organización propia de aquella sociedad del Madrid recién cristiano. Es fácil pensar en una organización similar a la de otras ciudades castellanas coetáneas, hecha la salvedad de la pujanza aquí mantenida por la comunidad mozárabe. El problema radica en que muy pocos de los viejos linajes llegaron puros o reconocibles por apellido al siglo xv.

De los principales prohombres que acompañaron a Alfonso VI cuando se produjo la capitulación o en años sucesivos, casi podemos asegurar que no se avecindó ninguno, aunque varios recibieron posesiones —el más notable, Per Ansúrez-; se justifica por no haber existido enclaves señoriales importantes en la Tierra de Madrid ni sus aledaños, salvo la concesión temporal de ciertas fortalezas por razones de seguridad, a más de algunos lugares, como Carabanchel, cuyos propietarios los liquidaron pronto.

La excepción pudieron constituirla caudillos destacados de las órdenes militares, principalmente calatravos, que entre los siglos XII-XIII tenían propiedades en el barrio de Santa María, y cuyos dominios rústicos esta- 
ban cercanos ${ }^{9}$. Así pues, la cúspide de la sociedad madrileña debió estar constituida por la nobleza media natural o importada. Ésta se compondría de los principales linajes mozárabes - de los que sólo conocemos dos o tres- y los más poderosos entre los foráneos. Pero muchos de los últimos poseen apellido patronímico, con lo que se dificulta la identificación. Excepciones notables fueron los Ramírez y Madrid —entre los mozárabes, pero que creemos extinguidos después, al menos en su rama principal- y los Vargas entre los repobladores. Éstos, que recibieron importantes propiedades y se dividieron en diversas ramas, son tal vez los únicos comprobados entre la nobleza antigua que llegan perfectamente identificados hasta el fin de la Edad Media. Indudablemente existieron más, pero la mezcla de linajes sólo permite albergar suposiciones.

Vendría luego un estrato inferior de hijosdalgo y caballeros, sin duda representativos, que son dueños de considerables extensiones de cultivo en los alrededores. Resulta complicado distinguirlos de los arrendadores de molinos, aceñas, salinas y de los comerciantes más destacados, y posiblemente puede incluirse a muchos en un grupo bastante homogéneo. Un sector pequeño, pero representativo, es el de artesanos y comerciantes, varios francos, que gozan de consideración social y figuran como jurados en las colaciones.

No faltaban los pequeños propietarios agrícolas, aunque fundamentalmente parecen residir en las aldeas o tener sus tierras en ellas. Sin embargo, da la sensación de que buena parte de los madrileños eran colonos, aparceros o criados; o sea, trabajadores en la agricultura y ganadería por cuenta ajena, de los caballeros o del clero. Muy pocos identificamos como siervos, lógico en lugar de propiedad relativamente repartida y donde se daba sólo un puñado de familias verdaderamente notables ${ }^{10}$. Este panorama bastante igualitario se alterará en la Baja Edad Media.

Ya se habló del efecto que tuvo sobre Madrid la presencia de la Corte. En cuanto a composición de su sociedad fue importante, empezando por la constitución de una poderosa nobleza local. De las seis decenas largas de linajes matritenses - algunos, fruto de ramificaciones- que nombra Quintana (1629), la inmensa mayoría era fruto del avecindamiento masivo registrado con los Trastámara. Sin embargo, queda claro que muchos de ellos quisieron encarecer sus orígenes en la villa, bien con relatos fabulosos o por medio de pretendidos enlaces con linajes extinguidos; aunque es cierto que en varios casos se dieron alianzas matrimoniales con

\footnotetext{
${ }^{9}$ Nos basamos sobre todo en los documentos de Fita (1886).

${ }^{10}$ Para una primera composición social, también nos fundamos en la documentación de Santo Domingo, supra.
} 
miembros de antiguas familias, con lo que los mayorazgos y apellidos se fundieron $o$ se incluyeron en otros.

Pongamos algunos ejemplos. Los Gudiel - de los primeros en establecerse-, procedentes de Toledo, llegaron a Madrid en tiempos de Pedro I; Luxanes y Zapata, aragoneses, se establecen con Juan I; por entonces también debieron venir los Ocaña; a los Gato - pese a leyendasno se los localiza anteriormente a Enrique III, como a los Mármol, provenientes de Inglaterra, y a los Herrera; Luzón y Córdoba debían estar aquí al menos desde Juan II, al igual que los Oviedo; otros varios llegaron ya con los Reyes Católicos, algunos de sangre regia, como los Castilla.

Como se ha dicho, varios enlazaron con viejos linajes. Pero otros, con una clase emergente afianzada desde fines del siglo XIV: los caballeros villanos. Entre este grupo de comerciantes enriquecidos estaban las ramas emparentadas de los Madrid y los Castillo, que pretendían descender del primer y auténtico linaje. También hubo hijosdalgo foráneos - Ramírezque se apuntaron a lo mismo.

A continuación de esta, en gran parte, nueva nobleza, se situaban - difíciles de deslindar de los hijosdalgo- los citados caballeros nuevos, unidos a la abogacía, los arrendamientos varios y el comercio. Por su caudal económico se permitían mantener armas y caballo y bastantes accedieron a la oligarquía municipal y obtuvieron privilegios de hidalguía. El siguiente paso era fundar capilla y un matrimonio con alguien que proporcionara lustre nobiliario. Pero sólo algunos — González de Madridllegaron a tanto, y realmente forman una escala flexible entre la aristocracia local y los comerciantes más modestos (Montero 1989; 1993; 1997) ${ }^{11}$.

Tras el grupo de aristócratas y el de caballeros y grandes comerciantes viene el de industriales de menores caudales y los menestrales. También aquí existían escalas, porque en los tres últimos decenios del siglo $\mathrm{xV}$ se percibe a la cabeza de este sector a los obligados, que arrendaban, mediante subasta a la baja, abastecimientos controlados por el Concejo, como vino, pescado y aceite (Monturiol 1985; Montero 1987: 310 y ss). A falta de más profundo estudio, no es fácil establecer barrera entre éstos, caballeros e incluso individuos de noble linaje que se disputan, hasta con ferocidad, arrendamientos y fuentes de ganancia de varia índole.

Al más bajo nivel del artesanado pueden asimilarse renteros, hortelanos y campesinos, e incluso servidores. La diferencia con tiempos anteriores consiste en la eclosión de la nobleza y lo que se suele llamar clases medias urbanas, que presentan una sociedad más avanzada y con más

${ }^{11}$ Tratamos el problema más por extenso en un trabajo sobre los Vargas, en curso de realización. 
matices, pero con acusados contrastes de poder y de renta entre estos dos grupos y el resto.

Como en cualquier población castellana de entonces, un sector influyente fue el clero, con su arcediano - que creemos pronto residente en Madridy su arcipreste a la cabeza. Tempranamente son mencionados clérigos en la villa, adscritos a determinadas parroquias, pero hasta fecha relativamente tardía no podemos establecer con cierta aproximación su número. En documento de 1409 -mal catalogado cronológicamente- aparece una reunión del cabildo de Madrid a la que asisten 17 sacerdotes, pero no están los de todas las parroquias ${ }^{12}$. Como en el siglo XV existían 13 colaciones, la cifra no debía bajar de la treintena, a lo que se añadirá el clero que prestaba sus servicios en hospitales y recogimientos, el prior y capellán -al menosresidentes en Santo Domingo y los frailes de San Francisco.

Esto, en lo referente a varones, pues en cuanto a mujeres tenemos 10 freylas -más religiosas de inferior categoría - que vivían en Santo Domingo ${ }^{13}$, amén de las franciscas de Santa Clara y las de los beaterios. Mas la población religiosa en el Medievo madrileño no alcanzó con mucho los extremos, proporcionados al número de instituciones piadosas, tangibles desde la segunda mitad del siglo xvI.

\subsection{Las minorías}

Ya hemos destacado que algunos musulmanes permanecieron, tras la anexión castellana, en la Morería tradicional en que se ubicaba la única mezquita de que conservamos tardía noticia. Sin embargo, cuando los mudéjares madrileños empiezan a aparecer asiduamente es a lo largo del siglo XIV. Estos moros de Madrid, en esta época, se repartían casi por todas las colaciones, aunque no hay razón para creer que abandonasen su ámbito de origen, y de hecho, unos pocos encontramos allí y en lugares inmediatos. Sus ocupaciones eran variadas. Tenemos una mora que es arrendadora de los célebres baños en las fuentes de San Pedro; también hallamos bodegueros, mesoneros, un tundidor, varios herreros especializados, carpinteros y, sobre todo - ¡cómo no!-, bastantes dedicados a oficios de la construcción: todos los alarifes del Concejo registrados a fines del $\mathrm{XV}$ son mudéjares.

En conjunto, la población islámica de la villa no parece haber gozado de mala situación. Parte significativa de ella estaba compuesta por artesa-

\footnotetext{
${ }^{12}$ AHN. Clero. 1361.20.

13 Ibid. 1364. 19. La cifra que exponemos es para 1420.
} 
nos de prestigio, a lo que algunos se acogen después de 1481, cuando por orden real un Concejo renuente se ve obligado a cercar y concentrar a moros y judíos. La aljama madrileña poseía cierto relieve, y en 1348 , un don Hamet es alcalde mayor de todas las aljamas del reino ${ }^{14}$.

Que la comunidad tenía vigor en el período que tratamos, se demuestra en la ocupación, desde poco antes de 1450, de la cava inferior junto a la plaza del Arrabal y del arranque del camino a Toledo. Este hecho, documentado por Urgorri (1953: 7 y ss, 23 y ss), dio lugar a la llamada Morería Nueva.

Los judíos, también de larga presencia, son menos mencionados hasta el siglo Xv. Si para algo vale -aunque nos tememos que las patrañas que los sitúan en Lavapiés, zona más que rural entonces, perduren-, señalaremos de nuevo que las noticias inmediatamente posteriores a la destrucción de su barrio en 1391 los emplazan entonces - ise habrían trasladado? - en la Almudena, entre el portal de Alvega y el Alcázar, donde en 1402-3 tenían su xinoga ${ }^{15}$. Documentación ulterior lo confirma.

Probablemente fueron menos que los musulmanes. En el Repartimiento de Huete (1290) ocupan puesto intermedio entre las aljamas del reino de Toledo, pero siempre hemos tildado de sospechoso tal documento, y sobre todo porque se basa en la capitación.

Varios hebreos encontramos como propietarios de terrenos y luego como arrendadores, traperos, especieros, y hasta personajes tan ilustres como los Romano o el famoso don Mayr Alguadix, pero el común debió distar mucho en cuanto a fortuna de sus correligionarios más favorecidos. Dos hechos similares lo prueban: en 1385 no tienen caudales para reparar la cerca de la Judería; casi una centuria después, los munícipes acuerdan pagar de los propios la tapia que ha de aislarlos del resto de la población.

Pero era prácticamente monopolio judío, como en otros lugares, un oficio noble: el de físico. Los titulares de la villa, desde que guardamos memoria, fueron siempre judíos hasta su expulsión (Montero 1987: 180-2; 191-5).

\section{COSTUmbres}

\subsection{La casa}

¿Dónde vivían los madrileños? Prácticamente ignoramos todo de los primeros tiempos. A lo sumo, alguna pincelada descriptiva tras el bastan-

\footnotetext{
${ }^{14}$ Ibid. 1360.2

15 Ibid. 1363.18; 1364.1.
} 
te corriente casas con su corral, que aparece más en las aldeas que en la villa; más concretas menciones hay a tiendas y casas tiendas.

Las primeras casas en que se pormenorizan unas obras aparecen en 1348 , pero se trata prácticamente sólo de las divisorias ${ }^{16}$. Es desde finales de esta centuria cuando encontramos someras descripciones en la colación de Xagra, referidas a viviendas bastante rústicas no sólo por poseer corral — circunstancia habitual también en las citadas en la Almudena-, sino por sus materiales y exiguas dimensiones. Estas últimas, por el precio y otros detalles, son más grandes y pertenecen a personas de mayor relieve. Otra tipología, sin duda, ofrecerían los inmuebles dedicados a actividades industriales y las casas-mesón, como las citadas en 1417 en la calle de la Ferrería, de las que se especifica que contaban con dos portadas ${ }^{17}$.

Mas en las viviendas de la Puerta de Guadalfajara y sus aledaños debía predominar otra tipología, precedente de la que imperará siglos después ${ }^{18}$. La causa era que se situaban en área comercial; poseían tres alturas y más —se habla de cámaras, sobrados y algorfas - , y en estos pisos de arriba se localizaba la zona habitada, pues en la planta baja estaba la tienda y el obrador, aunque éste a veces se hallaría en el entresuelo.

Se mencionan casas de nobles y gente acomodada, mas no poseemos detalles de su aspecto y distribución interior hasta mediados del siglo Xv. Creemos que para entonces se ha consolidado un tipo de mansión nobiliaria, caracterizada frecuentemente por complementarse con su torre. El ejemplo conservado es la de los Luxanes, aunque no edificada por este linaje, que parece corresponder al último cuarto del siglo XIV. El resto del conjunto no antecede a 1470 . Notable es la descripción de un edificio de 1472; se situaba junto a la Puerta de Guadalaxara y se habla de casas

$[\ldots]$ con un palaçio e un corredor e una saleta con una camara $[. . .]^{19}$.

Era vivienda importante por su emplazamiento y por su propietario. También por la circunstancia de que su censo, en principio muy moderado, alcanzaba ya entonces los 1100 maravedies y dos gallinas.

Algo a señalar es que, aunque parece que en principio la calidad de vecino estaba unida a la posesión de casa, al menos en el siglo XIV ya

${ }^{16}$ Ibid. 1360.2 .

17 Ibid. 1364.17.

${ }^{18}$ Exponemos este hecho por extenso en un libro sobre la calle Mayor de Madrid (col. Sambricio, C.), que esperamos ver en breve.

19 ARS. "Minutas de escribanos", III, 478 v. 
existía el alquiler. Ya en el siguiente, los contratos de arrendamiento constituyen moneda corriente (Montero 1992).

Más conocemos sobre el ajuar que contenían las viviendas. Acerca de lo que podía considerarse un equipamiento normal nos ilustra la donación que en 1390 realiza doña Flor a su criado, aparte de propiedades inmuebles: dos cubas de madera, de a cinco tinajas; diez de barro para contener vino so tierra; dos camas de rropa; una colcha; dos tinajeros; cuatro pares de sábanas; una caldera de arranbre; una sartén; media docena de tajaderos de madero; cuatro de tierra de Valençia; una docena de espetos de hierro ${ }^{20}$.

\subsection{La comida}

Al describir los primeros tiempos del agro madrileño hemos dado pistas sobre los componentes de la alimentación. Las continuas menciones a viñas y tierras de pan llevar, además de las especificaciones, nos hacen ver la importancia del vino, trigo, alcaçel, mijo, panizo. Componían con el aceite -aparecen olivos y almazaras - y los cultivos de huerta el eje de la nutrición.

La carne hubo de tener menor importancia. Hay carniceros - y pescadores-, pero no se citan tanto ganados, ejidos y pastizales. Tal vez en el consumo de vacuno pudo tener influencia la presencia de los repobladores: no sólo serían de utilidad los cueros. Pero más ilustrativos nos parecen los hallazgos arqueológicos, que denotan consumo importante de pollo, pequeñas aves y ovicápridos ${ }^{21}$.

Indudablemente en el Bajo Medievo la variedad fue mayor, y también el consumo proporcional de carne. Se aprecia en la necesidad de contratar obligados - como en otras ciudades- y la obsesión por buscar dehesas para el ganado; frecuentemente no se cubrían las necesidades de los consumidores. Se habla de 17 carneros diarios; en otra ocasión, de más de 500 anuales. En el bovino, la villa fue habitualmente deficitaria.

Podríamos elaborar estadística precisa sobre las fluctuaciones en el precio de la carne entre 1480 y 1500 . Ello nos permitiría conocer el género más apreciado por los madrileños. El rey era el carnero, que se cotizó entre 15-16 y 19 maravedies el arrelde. El puerco andaba sobre los 14, pero había escasez, salvo en el tiempo inmediato a la matanza. En las preferencias seguían el toro y la vaca; ésta se pagó entre 11 y 14 maravedíes y medio. Después, el cabrón y cabrito, aunque no poseemos

\footnotetext{
${ }^{20}$ AHN. Clero. 1362.16.
}

${ }^{21}$ Cf. supra, n. 4. 
tanta información sobre el precio. La oveja rara vez rebasó los 11 maravedíes por arrelde. La caza era muy estimada en su temporada. Está claro que no todos los vecinos accedían regularmente al consumo cárnico. Por ello eran tan solicitados los despojos: a 2 ó 3 maravedíes las cabezas y a 5 la asadura.

Si el volumen de carne despachada constituye buen índice para medir el aumento de población, podemos señalar que entre 1483 y 1500 creció en un 50-60\%. Mas no debe olvidarse una mejora en calidad de vida, pues por entonces registramos asimismo una aparición sensible de especieros, pasteleros y confiteros.

Como en el resto del interior peninsular, el pescado se consumía mucho menos. Mas también es consecuencia de la lejanía del mar. Su demanda aumentaba en Cuaresma y días de vigilia. Y, naturalmente, el remojado - traído y conservado en artesas con agua - era más caro y menos consumido que el salado o cecial. Se despachaba por libras, menos la sardina, y valía más que la carne: besugo y salazones alcanzaron hasta 8 maravedíes y el pulpo 6. Por ello se adquiría la morralla, que no solía llegar a la mitad.

Tocino y aceite fueron a veces géneros escasos, sobre todo el segundo, pero posiblemente por el enorme consumo; en ocasiones, hubo de buscarse aceite hasta en Andalucía. El empeño concejil en controlar harina y precios de cocción no evitó alzas y escasez en el bien más preciado, el pan: la ordenanza de 1498 estableció el precio del cuartal en un tope de 4 maravedíes. Era el máximo, pero resultaba proporcionalmente caro.

El vino también se controlaba férreamente; durante mucho tiempo sólo podían comercializarlo vecinos con sus propias viñas y se colocaron muchas trabas a los regatones o revendedores. Se distinguía entre vino normal y precioso. Existe un registro de tabernas de 1486 en que se reseñan 12 tabernas (¿sólo?). La entidad de éstas era bien diferente: una de ellas poseía más arrobas que todas las restantes; la de la Toribia, en cambio, contaba con una (Montero 1987: 310-23).

\subsection{La vida religiosa}

El madrileño de estos tiempos, como todo hombre medieval, era hombre religioso. No le faltaban, ciertamente, lugares ni ocasiones donde manifestar su piedad. Anteriormente nos referíamos a ello. Contaba la villa hacia 1510 con 13 parroquias, un número todavía no conocido de ermitas y humilladeros, 7 u 8 hospitales identificados —rastreamos noticias de hasta media docena más-, 7 conventos y monasterios y 1 recogimiento por lo menos. 
Sabemos de algunas devociones y cultos muy apreciados de los vecinos de Madrid. Entre las Vírgenes más veneradas estaban tradicionalmente las de la Almudena, Atocha y la de San Salvador. Era especialmente fuerte, de forma más o menos expresa, la devoción a la Inmaculada Concepción, sobre todo tras los solemnes votos de la villa en 1438 (Montero 1990). También por entonces se institucionalizaron altares y rogativas a diversos santos, con motivo de la pestilencia que, tras el temporal de lluvia poco anterior, asoló la población.

San Miguel, como en toda Castilla, era de los santos más considerados. No sólo constituía advocación de dos parroquias, sino que su festividad —que marcaba el fin de las labores agrícolas del estío e inauguraba las otoñales - era la elegida para ajustar los contratos anuales y cuando se elegían los oficios del Concejo. No deja de ser significativo que las celebradas en tal fecha sean las primeras actas municipales conservadas.

Por supuesto, y para la primera mitad del siglo $\mathrm{xv}$, podemos constatar cómo las principales familias matritenses habían labrado capilla en las parroquias de la villa y en los muy solicitados cenobios de San Francisco y Santo Domingo. Pero las mandas de otros particulares fueron muy abundantes, especialmente en el último citado. Conservamos muchos testimonios de últimas voluntades y donaciones pro anima, tanto por personas que allí se entierran como por otras que encargan misas, además de las que, tras la cesión de sus bienes, quieren acogerse, especialmente, al monasterio de dominicas.

Son los testamentos probablemente la fuente más importante para conocer la religiosidad madrileña en el declinar del Medievo. En ellos frecuentemente se incluyen donaciones a criados y menesterosos. Uno de los más completos es el de Ferrant Yuañes de 1283. Entre sus disposiciones envía dinero a los clérigos e iglesia de San Pedro; a los altares de Santa María de Tocha; también a Santa María de la Almudena y a sus clérigos, para capellán; luego destina una cantidad a inferior a todos los clérigos e iglesias de la villa; también se acuerda de otras iglesias de las aldeas. Pero, principalmente de Santo Domingo y de sus dueñas, así como otorga importantes cantidades y bienes raíces a parientes y servidores.

No se olvida, por supuesto, de su mujer, doña María Estevan, a la que deja casa y heredades; éstas pasarán, tras su muerte, a las dueñas de Santo Domingo. La condición que impone a la esposa es la habitual:

[...] en esta guisa que ella que tenga castidad e si non quel non valga la manda ${ }^{22}$.

${ }^{22}$ AHN. Clero. 1356.12. 
En tiempos de nula previsión social, ya sabemos que ésta dependía únicamente de quienes fundaban recogimientos u hospitales o quienes se acordaban de los desvalidos en sus testamentos. Un ejemplo es el de Diego Alfón, fechado en 1389:

[...] mando que den de comer a veynte pobres de Madrit, que les farte de pan y vino y carne o pescado [...] a cada ospital un lecho [...] cada uno una gerga [...] una coçedra y un cabezal y dos lençuelos y una manta y un sobrelecho.

Esto, puntualiza, está destinado a los pobres que acudieran a los hospitales.

Casi todas las últimas voluntades conservadas contienen fórmulas que constituyen el embrión de las empleadas siglos más tarde. Algunas, sin embargo - como la del propio Alfón-, y pese a términos comunes, son de una indudable grandeza en su exposición:

[...] conosiendo lo que veo y entendiendo lo que me dizen salvo la dolençia que Dios me quiso dar [...] et teniendo la [...] muerte como cosa natural para todos los omes del mundo[...] ofresco mi anima a Dios Padre ende por merced [?] la oue y el cuerpo a la tierra onde es natural $[\ldots]^{23}$

Tal vez estas solemnes palabras recojan mejor que nada la religiosidad de los madrileños del Bajo Medievo. Pueden constituir un excelente broche a lo que ha pretendido ser una visión de la sociedad matritense, de sus quehaceres y de su actitud vital en esta época.

\section{BIBLIOGRAFÍA CITADA}

Alvar EzQuerra, Alfredo. 1993. "Madrid en el siglo XVI", en A. Fernández García (dir.), Historia de Madrid: 139-86. Madrid: Editorial Complutense.

CAMPDERÁ GUTIÉRREZ, BEATRIZ y ANTONIO MANUEl MORAL RONCAL. 1993. "Aproximación a la organización del trabajo artesanal en Madrid a finales del siglo XV". Torre de los Lujanes XXIII: $135-49$.

Capella Medina, Miguel. 1962. La industria en Madrid. Estudio bistórico crítico de la fabricación y la artesanía madrileñas I. Madrid: Cámara de Comercio e Industria.

FITA ColOMER, FIDEL. 1886. "Madrid en el siglo XII" y estudios siguientes. Boletín de la Real Academia de la Historia VIII.

GONZÁlEZ y GONZÁLEZ, JULIO. 1975-6. Repoblación de Castilla la Nueva. Madrid, 2 vols. MARTORELl y TÉlLEZ-GIRón, RICARDo. 1930. Aproximación al estudio de la población de Madrid durante el siglo XV. Madrid.

Mendo Carmona, ConCEPCión. 1990. "La industria del cuero en la Villa y Tierra de Madrid a fin de la Edad Media. Espacio, Tiempo y Forma. Historia Medieval III: 181-211.

${ }^{23}$ Ibid. 1362.14 . 
Miguel Rodríguez, Juan Carlos De. 1989. La comunidad mudéjar de Madrid. Madrid: Ediciones La Librería.

MONTERO VALLEJO, MANUEL. 1986. Fundamentos, origenes y desarrollo urbano de Madrid hasta la Edad Moderna (tesis doctoral inédita).

- 1987. El Madrid medieval. Madrid: Editorial El Avapiés.

- 1989. "Diego González de Madrid, un prohombre madrileño del siglo XV". Anales del Instituto de Estudios Madrileños XXVI: 201-13.

- 1992. "Apuntes sobre la construcción y la vivienda en el Medievo madrileño". Anales del Instituto de Estudios Madrileños XXXI: 241-51.

- 1990. "La devoción concepcionista, un arraigado particularismo en el Madrid medieval.. Anales del Instituto de Estudios Madrileños XXVIII: 391-412.

- 1993. "Un siglo de crisis en Madrid". Torre de los Lujanes: 121-34.

- 1997. "Ruy Sánchez Zapata, la parroquia de San Miguel y la capilla de Nuestra Señora de la Estrella". Anales del Instituto de Estudios Madrileños XXXVII: 157-78.

MONTURIOL GONZÁLEZ, M. ÁNGELES. 1985. "El ingreso en la hacienda municipal de Madrid: estructura y evolución (1464-1497)». La ciudad hispánica (siglos XII-XVI) II. La Rábida-Sevilla.

PASTOR MATEOS, EnRIQUE. 1950. "Noticias sobre la organización profesional de Madrid en la Edad Media". Revista de la Biblioteca, Archivo y Museo del Ayuntamiento de Madrid XIX: 261-89.

PuÑal FERNÁNDEZ, TOMÁs. 2000. Los artesanos de Madrid en la Edad Media (1200-1474). Madrid: UNED.

QuintanA, JeRÓNImo DE. 1629. A la muy Antigua, Noble y Coronada Villa de Madrid. Historia de su Antigüedad, Nobleza y Grandeza. Madrid.

URGorri CASADO, FERnANDO. 1953. "El ensanche de Madrid en tiempos de Enrique IV y Juan II; la urbanización de las cavas". Revista de la Biblioteca, Archivo y Museo del Ayuntamiento de Madrid XXIII: 3-63. 